\title{
Antibiotic Abuse: A Cross-Sectional Study on Knowledge, Attitude, and Behavior Among the University Students in Dhaka, Bangladesh
}

\author{
Md. Hasanul Banna Siam ${ }^{1}$, Ashik Imran ${ }^{1}$, Md. Belayet Hasan Limon ${ }^{1}$, Mehedi Hasan Zahid ${ }^{1}$, Md. Azmir Hossain ${ }^{2}$, \\ Mohammad Anwar Siddique ${ }^{1}$, Munawar Sultana ${ }^{1}$, M. Anwar Hossain $1,3^{*}$
}

\begin{abstract}
Department of Microbiology, University of Dhaka, Dhaka, BANGLADESH
${ }^{2}$ Department of Statistics, University of Dhaka, Dhaka, BANGLADESH

${ }^{3}$ Jashore University of Science and Technology, Jashore, BANGLADESH

*Corresponding Author: hossaina@du.ac.bd
\end{abstract}

Citation: Siam MHB, Imran A, Limon MBH, Zahid MH, Hossain MA, Siddique MA, Sultana M, Hossain MA. Antibiotic Abuse: A Cross-Sectional Study on Knowledge, Attitude, and Behavior Among the University Students in Dhaka, Bangladesh. Electron J Gen Med. 2021;18(3):em289. https://doi.org/10.29333/ejgm/10836

\section{ARTICLE INFO}

Received: 18 Oct. 2020

Accepted: 7 Apr. 2021

\begin{abstract}
Objective: Antibiotic abuse has contributed to the development of antimicrobial resistance (AMR) and has become a global concern. With a poorly regulated health system and a general lack of data, Bangladesh remains under high risk of AMR spread. To minimize the existing gap in the literature, this study was conducted to assess the knowledge, attitude, and behavior regarding antibiotic use and misuse among university students.

Methods: A cross-sectional study design was used to survey 1400 students using a self-administered questionnaire from the University of Dhaka, Bangladesh. Descriptive and inferential analyses were performed with statistical significance defined as $\mathrm{p}<0.05$.

Results: More than half of the respondents had poor knowledge and neutral attitude towards antibiotics. The students from bioscience were found to have better knowledge and attitude than arts and business. Respondents with good knowledge were more likely to show a positive attitude, $p<0.05$. Most of the respondents did not know that antibiotics are ineffective against most coughs and cold; and above $60 \%$ practiced self-medication. About one-third did not know that antibiotics mainly target bacteria, and surprisingly, more than four-fifth perceived that humans \& animals could become resistant to antibiotics. Also, half of the participants did not fulfill their prescribed antibiotic course.

Conclusion: There is a substantial amount of knowledge and attitude gap about and non-compliance to the proper use of antibiotics among the university students. The research findings, therefore, reflect the need for policy-level interventions to increase awareness and develop effective countermeasures to prevent the misuse of antibiotics.
\end{abstract}

Keywords: antibiotic resistance, Bangladesh, abuse, self-medication, university students

\section{INTRODUCTION}

Antimicrobials once coined as the 'magic bullet', are now rendered futile to fight bacterial infections as antimicrobial resistance (AMR) has emerged as a global threat to public health. Inappropriate and rampant use of such invaluable lifesaving drugs is among the key factors for the rapid development of superbugs and subsequent treatment failures with increased mortality rates [1]. Unless effective measures are taken, a substantial amount of death could occur globally due to antibiotic resistance [2]. The developing countries are at greater risk primarily due to irrational consumption of antibiotics, non-human antibiotic use, limited knowledge regarding AMR, malnutrition, inapt surveillance, and poor healthcare standards [3]. Besides, inadequacy in developing newer drugs implies that the existing options should be pursued for the rational use of antibiotics to maximize the therapeutic benefits.
The use and misuse of antibiotics largely differ across countries influenced by social and cultural perception [4]. Purchase of antibiotics from pharmacies without a valid prescription, self-medication, partial fulfilment of the course and sharing left-over antibiotics are among the common malpractices. In a global study conducted in 11 countries, 22\% of the adult respondents admitted to non-compliance to antibiotic therapy [5]. The role of the physicians is also in question at times as they are requested and pressurized to prescribe antibiotics both by the aggressive drug marketing policy and by the patients as a means for quick relief in trivial reasons.

Like most other developing countries, Bangladesh also faces the challenge of AMR and is inflicted with infections owing to the widespread presence of multi-drug resistant (MDR) and extensive-drug resistant (XDR) bacterial strains. A study on children from rural areas of Bangladesh showed that more than 80 per cent had MDR Escherichia coli bacteria in their gut [6]. Presence of MDR Staphylococcus aureus was also 
confirmed in ready-to-eat foods, processed raw meat and fish samples from retail vendors in Dhaka city [7]. A substantial number of pharmacies is non-licensed, and the sellers have little-to-no formal training about the use of antibiotics. Consumption of antibiotics for acute respiratory infections (ARI) including cold, cough and viral flu is a common scenario as both patients and drug sellers are unaware of the risks linked to the needless medication [8]. In line with the WHO (World Health Organization) guidelines, one way to minimize excessive antibiotic use is by improving the knowledge and prescribing actions of healthcare practitioners [9]. Although physicians play a key role in the choice and use of medicine, the awareness of the patients is also equally important [10]. So, addressing the current states of public awareness and perception helps identify the point at issue and provides comparable data to influence decisions to be sought in the healthcare systems. Since epidemiological data on this theme is scarce in Bangladesh, it necessitates to fill up the void of information. Thus, this study was designed: (i) to evaluate the knowledge, attitude and behavior about the proper use of antibiotics among the university students who represent the educated class in the society, (ii) to determine whether the field of study influences attitude or behavior towards antibiotics, and (iii) to identify which groups within the population require improved awareness.

\section{MATERIALS AND METHODS}

\section{Study Site, Population and Sample Size}

A cross-sectional study was conducted the University of Dhaka, Bangladesh, from July 2018 to October 2018 involving university students of both undergraduate and graduate level. The university holds 13 faculties, 83 departments, 12 institutes and 20 residential halls in which 37,018 students are actively studying. As Bangladesh's largest public university in terms of population, it serves as the epicenter of higher education that includes students of diverse backgrounds coming from all over the country.

For the study, the sample size was calculated using the Raosoft online sample size calculator (www.raosoft.com) by assuming a 95\% confidence level, 3\% margin of error and 50\% response distribution. The minimum recommended sample size was 1038 . Assuming a response rate of $50 \%$, the sample size was enlarged to 1600 students to improve reliability, of which 1400 data were enrolled in the final analysis after careful removal of incomplete questionnaires.

\section{Survey Instrument and Data Collection}

The data were collected using a structured questionnaire developed based on literature review and expert opinions to assess knowledge, attitude, and behavior towards antibiotics among the university students. Based on an earlier questionnaire developed by Vallin et al, our questionnaire consisted of 5 modules: (a) antibiotic consumption, (b) antibiotic accessibility, (c) antibiotic use and its effects, (d) side effect and resistance, and (e) patient experience (4). The internal consistency reliability of the questionnaires was checked, and their Cronbach's Alpha value was 0.72. In addition to the queries on basic demographics, there were 30 questions distributed equally for the assessment of knowledge $(\mathrm{K})$, attitude (A) and behavior (B). There was also an openended question. In the case of the field of study, the university departments were sorted into larger simplified categories of "Arts", "Business", "Bioscience", and "Physical Science" for the ease of analysis.

The convenience sampling method was used to approach students to complete a self-administered questionnaire. The inclusion criterion was that the participants belonged to the University of Dhaka and were currently enrolled at either undergraduate or graduate level. To increase the generalizability of the study, the students were approached in classrooms, cafeterias, libraries, open space, halls, university buses and via social networks using 'google form'. The google form, however, was distributed through personal communication. The data from both hardcopies $(n=1106)$ and online forms $(n=294)$ were included in the analysis.

\section{Statistical Analysis}

A scoring system was applied to measure the respondents' knowledge and attitudes towards antibiotics. For each correctly chosen choice to a question, a value of ' 1 ' was awarded, whereas both wrong and "don't know" response had a value of ' 0 '. Participants' overall knowledge was categorized based on the response to 10 statements using modified Bloom's cut-off point, as good if the score was between 80 and $100 \%$ (8-10 points), moderate if the score was between 50 and $79 \%$ (5-7 points), and poor if the score was less than 50\% (0-4 points). The attitude was categorized in the same way using responses to 10 statements based on the score between 80 and $100 \%$ (8-10 points) as positive, neutral if the score was between 50 and $79 \%$ (5-7 points), and negative if the score was less than 50\% (0-4 points).

Data were entered manually and analyzed in SPSS Software Version 25 (SPSS Inc., Chicago, IL, USA). The descriptive statistics was used to measure central tendency and dispersion (mean, median and range) and to obtain frequencies and percentages for categorical variables. Crosstabulation with Pearson's chi-square test was performed for testing association between categorical data. It was hypothesized that there was variation in the knowledge and attitude of the participants with respect to their field of study. Since the scores were not normally distributed based on the Shapiro-Wilk test, a non-parametric test of difference (Kruskal Wallis $\mathrm{H}$ test and median test) at the level of significance $(\alpha)$ of 0.05 was carried out. The missing values for the cases were excluded listwise. Binary logistic regression analyses were conducted, odds ratios and $95 \%$ confidence intervals were estimated, and a p-value $\leq 0.05$ was considered statistically significant.

\section{Ethical Consideration}

In this survey, no vulnerable groups were included, and the study did not involve the risk of psychological or informational harms. The study protocol followed the 1964 declaration of Helsinki and its later amendments. Signed informed consent was obtained from the participants. They were adequately informed of the nature and purpose of the study, of the right to withdraw their data, and were assured of maintaining the confidentiality of the data being used in the research. Those who agreed to voluntarily take part in the study were given the survey forms. On average, the participants required only 15 minutes to complete the questionnaire. 
Table 1. Demographic characteristics of the respondents, $(n=1400)$

\begin{tabular}{|c|c|}
\hline Characteristics & n (\%) \\
\hline \multicolumn{2}{|l|}{ Sex } \\
\hline Male & $845(60.4 \%)$ \\
\hline Female & $555(39.6 \%)$ \\
\hline \multicolumn{2}{|l|}{ Study Level } \\
\hline Undergraduate & $1174(83.9 \%)$ \\
\hline Graduate & $226(16.1 \%)$ \\
\hline \multicolumn{2}{|l|}{ Age } \\
\hline$<20$ & $283(20.2 \%)$ \\
\hline $20-25$ & $1065(76.1 \%)$ \\
\hline$>25$ & $52(3.70 \%)$ \\
\hline \multicolumn{2}{|l|}{ Faculty } \\
\hline Arts & $607(43.4 \%)$ \\
\hline Business & $154(11.0 \%)$ \\
\hline Bioscience & $290(20.7 \%)$ \\
\hline Physical Science & $349(24.9 \%)$ \\
\hline
\end{tabular}

Table 2. Respondents' knowledge regarding antibiotics $(n=1400)$

\begin{tabular}{lcc}
\hline Items & Correct & Incorrect \\
\hline 1. Antibiotics are supposed to kill - (Bacteria) & $479(34.2 \%)$ & $921(65.8 \%)$ \\
\hline 2. Antibiotics make one recover faster when having a cold- (D) & $280(20 \%)$ & $1120(80 \%)$ \\
\hline 3. Antibiotics often cause side effects e.g. diarrhea, stomach upset - (A) & $1092(78.0 \%)$ & $308(22.0 \%)$ \\
\hline 4. Antibiotics cause harm on the body's gut microbiota - (A) & $812(58 \%)$ & $588(42 \%)$ \\
\hline 5. One can terminate a partially completed antibiotic therapy after feeling better - (D) & $705(50.4 \%)$ & $695(49.6 \%)$ \\
\hline 6. Bacteria can become resistant to antibiotics- (A) & $829(59.2 \%)$ & $571(40.8 \%)$ \\
\hline 7. The more we use antibiotic, the higher the risk that resistance develops - (A) & $927(66.2 \%)$ & $473(33.8 \%)$ \\
\hline 8. Human and animal can become resistant to antibiotics- (D) & $213(15.2 \%)$ & $1187(84.8 \%)$ \\
\hline 9. Use of antibiotics for animals can reduce effectiveness of human antibiotic treatment- (A) & $465(33.2 \%)$ & $935(66.8 \%)$ \\
\hline 10. Antibiotic resistance can spread from animal to human - (A) & $564(40.3 \%)$ & $836(59.7 \%)$ \\
\hline Correct Answer: A = Agree; D = Disagree & &
\end{tabular}

\section{RESULTS}

A total of 1600 students at the University of Dhaka were approached; out of which 1442 agreed to participate in the study making a response rate of $90.1 \%$. However, $2.9 \%$ of the data were discarded due to incompleteness and inadequate responses. More male $(60.4 \%)$ and undergraduates $(83.9 \%)$ responded to this survey who were mainly in the age group of 20-25 years with a mean age of $21 \pm 0.5$ years. Table 1 summarizes the general characteristics of the respondents.

More than sixty-five per cent students were incorrect about the antibiotic target choosing "both bacteria and virus" (31.6\%), "all pathogens" (10.4\%), "virus" only (6.8\%) - and about $17 \%$ of them responded that they did not know the answer. While the majority (78\%) said that antibiotics could cause side effects, but more than $50 \%$ of the respondents said that they could terminate the antibiotic therapy without fulfilling the course in case of feeling better. The awareness about the antibiotics' side effect might be ironically related to partial fulfilment of the antibiotic course, $X 2(4, N=1400)=$ $37.42, p<0.05$, as students could wrongly stop taking antibiotics in fear of side effects.

The responses to questions related to antibiotic resistance also showed an overall poor knowledge among the students. Although about $60 \%$ (829) were correct about bacteria becoming resistant to antibiotics, about $85 \%$ (1187) incorrectly said that human and animals could also become resistant to antibiotics. The majority $(836 ; 59.7 \%)$ of the respondents did not know that resistance could develop and spread from animal to human or vice versa. Table 2 shows the correct and incorrect responses in knowledge-based questions.

More than $75 \%$ of the participants agreed positively that it is incorrect to acquire antibiotics from relatives without being examined by a doctor. They also positively answered that it is neither okay to take an antibiotic prescription from a doctor via phone (892; 63.7\%), nor by the suggestion of the medicine seller of the pharmacy $(1105 ; 78.9 \%)$. In response to the attitude question that stated about the leftover antibiotics, about 48\% (670) respondents disagreed to save antibiotics for future use, whereas about $25 \%$ was unsure as what to do and $27.5 \%$ agreed to save leftover antibiotics for personal use or to give to someone else.

A negative attitude was recorded in response to the statement: "a persistent cough (longer than one week) always needs to be treated with antibiotics to heal" as $41.2 \%$ of the respondents incorrectly agreed to it followed by $31.3 \%$ disagreements and $27.5 \%$ being unsure. About $48 \%$ of students think that it is not appropriate to self-medicate antibiotics for diarrhea, and about two-thirds (66.2\%) agreed that the body can usually fight mild infections on its own without antibiotics. It is noteworthy that the majority of the participants (980; $70.2 \%$ ) think that antibiotic resistance is now a big problem for Bangladesh (Table 3).

In terms of knowledge, a median score of 4 (IQR: 3) was obtained out of a maximum possible score of 10 , which demonstrated poor knowledge about antibiotics, its use, and resistance. Overall, more than half $(50.1 \% ; 715)$ of study respondents belonged to the category of poor knowledge, followed by moderate knowledge (40.2\%; 564) and good 
Table 3. Respondents' attitude towards use of antibiotics $(n=1400)$

\begin{tabular}{lccc}
\hline Items & Agree & Disagree & Unsure \\
\hline 1. Leftover antibiotics can be saved for future use or to give to someone else & $384(27.4 \%)$ & $670(47.9 \%)$ & $346(24.7 \%)$ \\
\hline 2. Leftover antibiotics should be taken back to the pharmacy & $649(46.4 \%)$ & $353(25.2 \%)$ & $398(28.4 \%)$ \\
\hline 3. It is good to be able to acquire antibiotics from relatives or acquaintances & $202(14.4 \%)$ & $1059(75.6 \%)$ & $139(9.9 \%)$ \\
\hline 4. It is good to buy antibiotics from pharmacies without a prescription & $160(11.4 \%)$ & $1131(80.8 \%)$ & $109(7.8 \%)$ \\
\hline 5. The body can usually fight mild infections on its own without antibiotics & $926(66.1 \%)$ & $155(11.1 \%)$ & $319(22.7 \%)$ \\
\hline 6. A persistent cough (>1 week) always needs to be treated with antibiotics & $577(41.2 \%)$ & $438(31.3 \%)$ & $385(27.5 \%)$ \\
\hline 7. It is appropriate to take antibiotics for diarrhea on my own & $271(19.4 \%)$ & $670(47.9 \%)$ & $459(32.8 \%)$ \\
\hline 8. Today, antibiotic resistance is a big problem in Bangladesh & $980(70.0 \%)$ & $103(7.4 \%)$ & $317(22.6 \%)$ \\
\hline 9. It is okay to be able to take antibiotic prescription from a doctor via phone & $381(27.3 \%)$ & $892(63.7 \%)$ & $127(9.1 \%)$ \\
\hline 10. It is okay to take antibiotics based on the suggestion of a medicine seller & $174(12.4 \%)$ & $1105(78.9 \%)$ & $121(8.6 \%)$ \\
\hline
\end{tabular}

Knowledge towards antibiotics across four different fields of study, $n=1400$

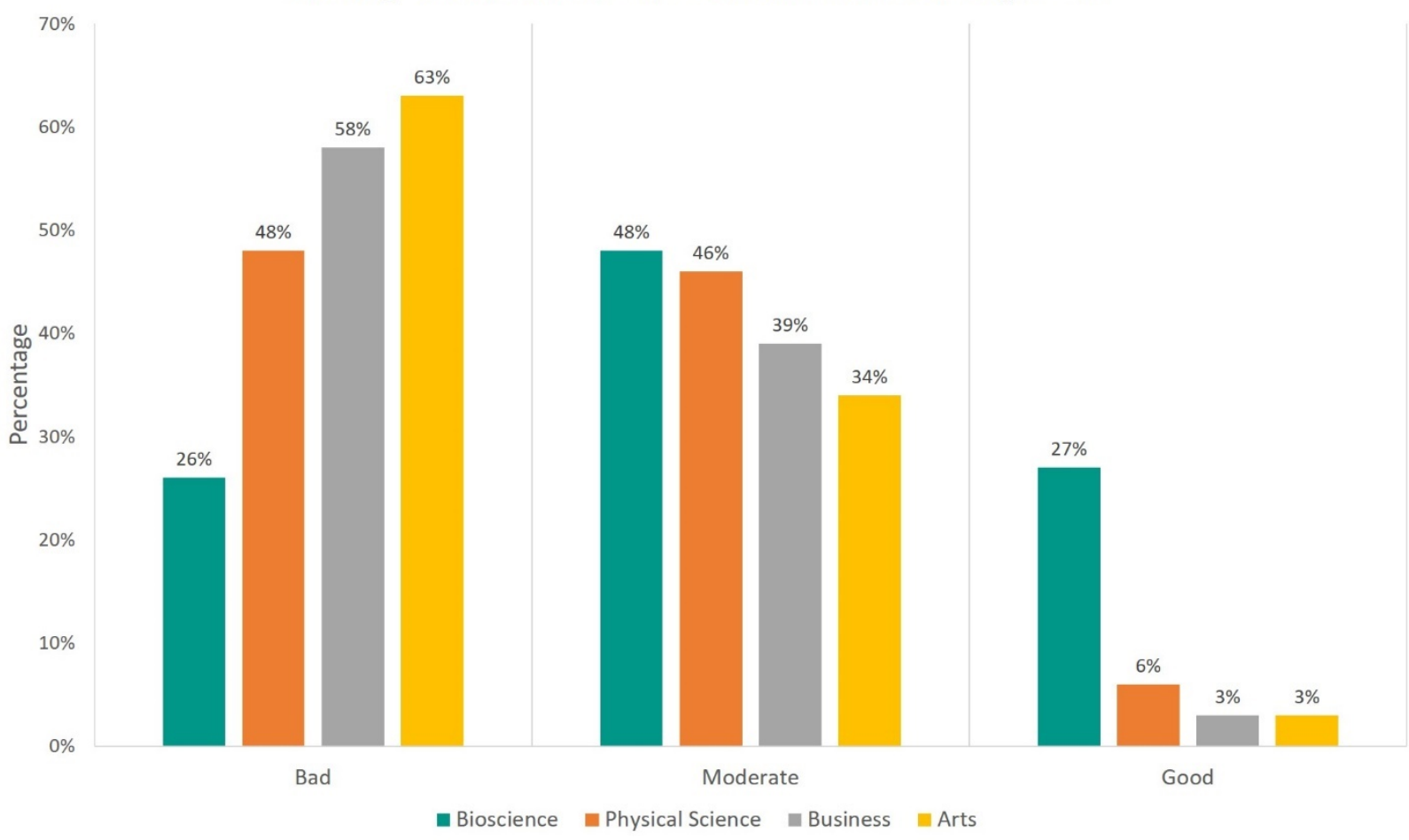

Figure 1. Distribution of knowledge towards antibiotics across four different fields of study, $N=1400$

knowledge $(8.7 \% ; 121)$. Students from bioscience had better knowledge $(26.5 \% ; \mathrm{N}=290)$ about antibiotics than physical Science (6.3\%; $N=349)$, arts $(2.96 \% ; N=607)$ and business (2.59\%; $\mathrm{N}=154)$ faculty (Figure 1 ).

The overall median attitude score was 7 (IQR: 3) out of a maximum possible score of 10 , which indicated a neutral attitude (51.3\%; 718$)$. The positive attitude $(29.4 \%$; 411$)$ was higher as opposed to the negative attitude (19.4\%;271). Among the faculties, bioscience had more positive attitude (44.82\%; N $=290)$ followed by physical Science $(30.08 \% ; \mathrm{N}=349)$, business (24.6\%; $\mathrm{N}=154)$ and arts (22.73\%; $\mathrm{N}=607$ ) faculty (Figure 2).

In Kruskal-Wallis $\mathrm{H}$ test, a statistically significant difference was found between the knowledge scores and the faculties, $x 2$ $(3, N=1400)=116.68, p<0.05$, with a mean rank knowledge score of 941.20 for bioscience, 718.51 for physical science, 603.30 for business and 599.81 for arts. Similarly, a statistical significance was also found between attitude scores and the faculties, $\mathrm{X} 2(3, \mathrm{~N}=1400)=48.02, \mathrm{p}<0.05$, with a mean rank attitude score of 846.86 for bioscience, 716.98 for physical science, 696.19 for business and 622.19 for arts (Table 4).
In logistic regression analysis, respondents with good knowledge were more likely to show a positive attitude (OR: 4.62; $\mathrm{Cl}: 3.05-7.05 ; \mathrm{p}<0.05)$. The students from the faculty of science (OR: 2.11; Cl: 1.66-2.69; $\mathrm{p}<0.05$ ), and particularly of bioscience were found to be more knowledgeable than those from other faculties (OR: 8.89; $\mathrm{Cl}$ : 5.95-13.30; $\mathrm{p}<0.05$ ). Two independent variables had an influence on the respondents' overall attitude towards the use of antibiotics. Students in the age range of 20-25 years (OR: $1.76 ; \mathrm{Cl}: 1.21-2.57 ; \mathrm{p}=0.003$ ) and those from bioscience faculty were more likely to show favorable attitude (OR: 2.87; Cl: 1.88-4.39; $\mathrm{p}<0.05$ ). No other independent variables showed any significant association to influence respondents' knowledge or attitude level.

In terms of behavior, $94.3 \%$ of students reported that they consumed antibiotics - the majority of which was due to fever (53.2\%), bacterial infection (21.1\%) and cold (15.7\%). More than one-third (34.8\%) of the respondents took antibiotics for once in the past 12 months, and about $30.3 \%$ took it for two to five times. About half (49.3\%) of the respondents said that they completed the antibiotic course while about $35 \%$ did not do the same. Respondents with good knowledge were more likely 


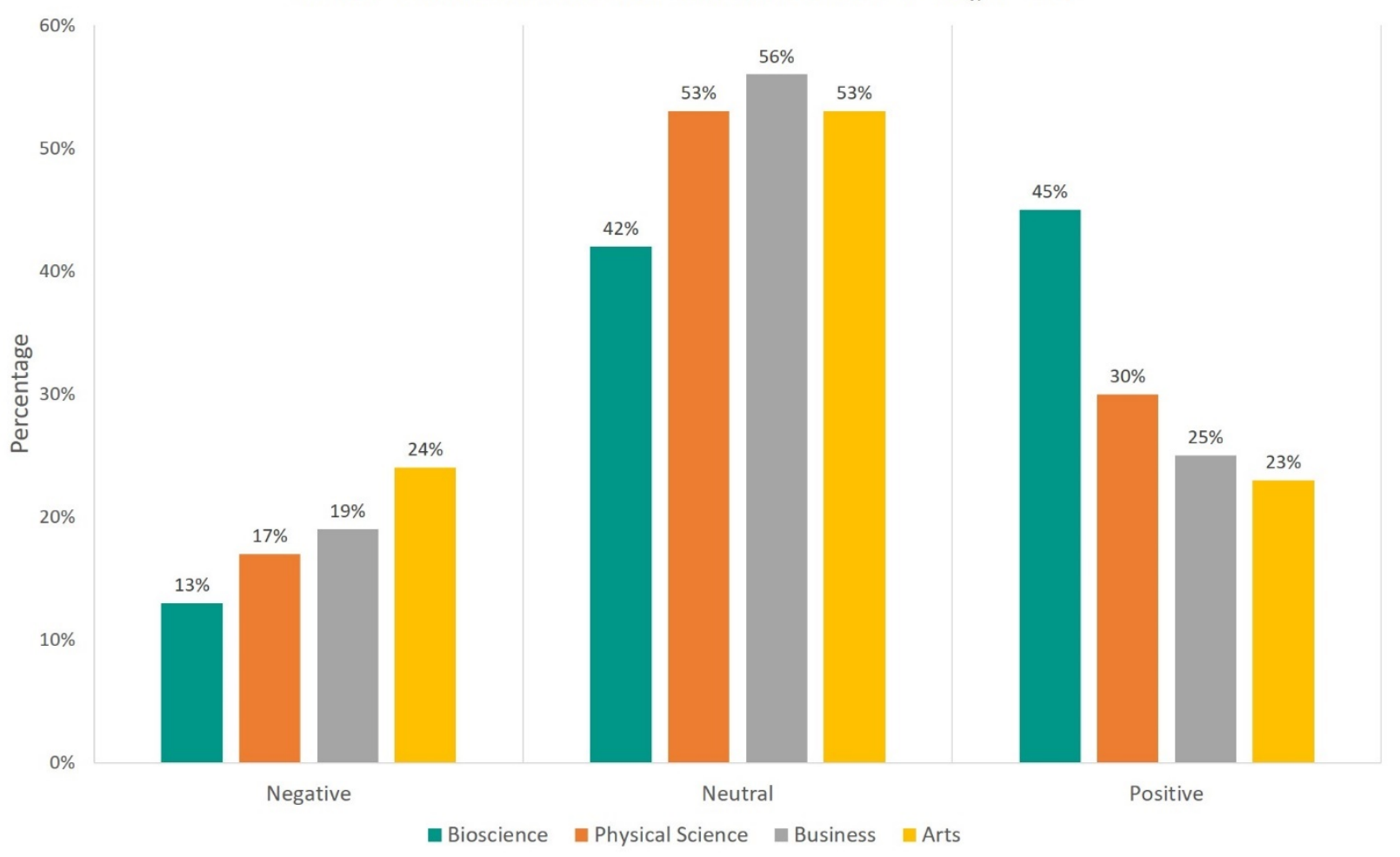

Figure 2. Distribution of attitude towards antibiotics across four different fields of study. $N=1400$

Table 4. Kruskal Wallis test to compare the respondents' knowledge and attitude score variation across the four different fields of study, $2018(n=1400)$

\begin{tabular}{|c|c|c|c|c|c|c|c|}
\hline & \multicolumn{7}{|c|}{ Knowledge and attitude score classified by faculty } \\
\hline & Faculty & Frequency & Median (IQR) & $\begin{array}{c}\text { Mean rank } \\
\text { (R) }\end{array}$ & df & $\begin{array}{c}\text { Kruskal-Wallis } \\
\text { (H) }\end{array}$ & Test statistics \\
\hline \multirow[t]{4}{*}{ Knowledge score } & Bioscience & 290 & $6(4)$ & 941.20 & \multirow{4}{*}{3} & \multirow{4}{*}{153.256} & \multirow{4}{*}{$\begin{array}{c}x^{2}(3)=116.68 \\
p<0.05 \\
n=1400\end{array}$} \\
\hline & Physical Science & 349 & $5(3)$ & 718.51 & & & \\
\hline & Business & 154 & $4(2)$ & 603.30 & & & \\
\hline & Arts & 607 & $4(2)$ & 599.81 & & & \\
\hline \multirow[t]{4}{*}{ Attitude score } & Bioscience & 290 & $7(2)$ & 846.86 & \multirow{4}{*}{3} & \multirow{4}{*}{62.868} & \multirow{4}{*}{$\begin{array}{c}\mathrm{x}^{2}(3)=48.021 \\
p<0.05 \\
\mathrm{n}=1400\end{array}$} \\
\hline & Physical Science & 349 & $7(3)$ & 716.98 & & & \\
\hline & Business & 154 & $7(2)$ & 696.19 & & & \\
\hline & Arts & 607 & $6(2)$ & 622.19 & & & \\
\hline
\end{tabular}

The difference is significant at $\alpha=0.05$ (i.e., $x^{2}=9.488$ )

to complete the antibiotic course (OR: 2.04; Cl: 1.32-3.15; $\mathrm{p}=0.001)$. Although more than $50 \%$ of the students had direct experience of buying antibiotics from pharmacy, most of the participants $(72.1 \%)$ responded that their recent purchase of antibiotics was done based on the prescription of a registered doctor. However, in response to a multiple-choice question to choose a common antibiotic name, about two-thirds (65.4\%; 900 ) of the students identified azithromycin, followed by the wrong choice of paracetamol $(18.5 \% ; 255)$ and omeprazole $(7.6 \% ; 104)$ as antibiotics. Self-medication was excessively high among students as more than $60 \%$ reported that they had an experience of prescribing antibiotics for themselves and their kin. No independent variable was found to influence selfmedication among students (Table 5 ).

In response $(n=320)$ to the open-ended question of mentioning the name of any known antibiotic, azithromycin $(32 \%)$ was found to be the most frequent choice, followed by ciprofloxacin (9\%), amoxicillin (7\%), penicillin (4\%), cefixime (4\%), and metronidazole (2\%). Notably, omeprazole (3\%), fluconazole (2\%) and paracetamol (11\%) were also perceived as antibiotics by the participants.

\section{DISCUSSION}

Bangladesh as a developing country has seen some rapid growth recently and managed to overcome many of the challenges in the health sector. Yet, population-based studies to explore knowledge, attitudes and behavior towards antibiotic use and misuse are scarce, and the lack of data cannot aid in policy development [11]. Hence our study is one of the few attempts in the literature to assess the status of university students regarding antibiotics in the context of Bangladesh.

In this study, the respondents showed poor knowledge compared to other countries such as Malaysia, Trinidad and Tobago but better than Lithuania and Ethiopia [12-15]. Since adequate knowledge translates into a positive attitude, so 
Table 5. Respondents' behavior towards antibiotic use

\begin{tabular}{|c|c|}
\hline Items & n (\%) \\
\hline \multicolumn{2}{|c|}{ 1. Have you ever taken Antibiotics? $(n=1400)$} \\
\hline - Yes & $1320(94.3 \%)$ \\
\hline - No & $57(4.1 \%)$ \\
\hline - Don't know & $23(1.6 \%)$ \\
\hline \multicolumn{2}{|c|}{ 2. Reason of taking antibiotic $-(n=1372)$} \\
\hline - Cold & $215(15.7 \%)$ \\
\hline - Flu & $55(4.0 \%)$ \\
\hline - $\quad$ Fever & $730(53.2 \%)$ \\
\hline - $\quad$ Bacterial Infection & $290(21.1 \%)$ \\
\hline - Other & $82(6.0 \%)$ \\
\hline \multicolumn{2}{|c|}{ 3. How many times did you consume antibiotics in the past 12 months? $(n=1393)$} \\
\hline - None & $486(34.9 \%)$ \\
\hline - Once & $485(34.8 \%)$ \\
\hline-2 to $>5$ times & $422(30.3 \%)$ \\
\hline \multicolumn{2}{|c|}{ 4. Do you always fulfill the antibiotic course? $(n=1389)$} \\
\hline - Yes & $685(49.3 \%)$ \\
\hline - No & $484(34.8 \%)$ \\
\hline - I can't remember & $220(15.8 \%)$ \\
\hline \multicolumn{2}{|c|}{ 5. Did you make your recent purchase of antibiotics based on a doctor's prescription? ( $n=1345)$} \\
\hline - Yes & $970(72.1 \%)$ \\
\hline - No & $289(21.5 \%)$ \\
\hline - Don't Know & $86(6.4 \%)$ \\
\hline \multicolumn{2}{|c|}{ 6. I have experience of acquiring prescribed antibiotics from a pharmacy - $(n=1397)$} \\
\hline - Agree & $777(55.6 \%)$ \\
\hline - Disagree & $467(33.4 \%)$ \\
\hline - Don't Know & $153(11.0 \%)$ \\
\hline \multicolumn{2}{|c|}{ 7. I have experienced antibiotic prescription for myself or my kin - $(n=1396)$} \\
\hline - Agree & $856(61.3 \%)$ \\
\hline - Disagree & $364(26.1 \%)$ \\
\hline - Don't Know & $176(12.6 \%)$ \\
\hline \multicolumn{2}{|c|}{ 8. I usually know how antibiotics should be taken - $(n=1397)$} \\
\hline - Agree & $656(47.0 \%)$ \\
\hline - Disagree & $422(30.2 \%)$ \\
\hline - Don't Know & $319(22.8 \%)$ \\
\hline \multicolumn{2}{|c|}{ 9. Doctors run a thorough examination of whether a patient needs antibiotics or not- $(n=1400)$} \\
\hline - Agree & $739(52.8 \%)$ \\
\hline - Disagree & $449(32.1 \%)$ \\
\hline - Don't know & $212(15.1 \%)$ \\
\hline \multicolumn{2}{|c|}{ 10. Doctors prescribe antibiotic when a patient expects it $-(n=1398)$} \\
\hline - Agree & $544(38.9 \%)$ \\
\hline - Disagree & $622(44.5 \%)$ \\
\hline - Don't know & $232(16.6 \%)$ \\
\hline
\end{tabular}

good knowledge among the respondents is an important parameter for community awareness about antibiotics [16]. Understanding the proper antibiotic target is also important as it indicates knowledge about antibiotic use and helps prevent irrational consumption. But, the majority (>65\%) of the participants failed to identify bacteria as the correct antibiotic target. This misconception is higher than what was found in the studies in Sweden, Nepal, Ethiopia, Kuwait, UK, Lithuania, and Taiwan, ranging from $6.3 \%$ to $60.8 \%$ except for Jordan (67\%) $[4,10,14,15,17-20]$. Alarmingly, about half of the participants thought that it was okay to terminate the antibiotic therapy after starting to feel better, and more than one-third admitted about not completing the dose. In Pakistan, Saudi Arabia, Taiwan, Syria, Nigeria and Jordan, about $42 \%$ to $60 \%$ people stopped taking antibiotics after the symptoms disappeared, whereas the malpractice was close to $15 \%$ in Nepal and Italy $[10,19,21-26]$. The abuse in antibiotic course completion may put the patient at the risk of relapsing infections with probability for the development of resistance. Although antibiotics are ineffective against most coughs and cold, $80 \%$ of the respondents did not know about it. This finding is higher than Jordan, Ethiopia, Kuwait, Nigeria, Taiwan, Sweden varying from $67 \%$ to $13.4 \%[4,10,15,18,20,24]$.

In case of knowledge regarding antibiotic resistance, the majority ( $85 \%$ ) expressed that human and animal can become resistant to antibiotics which is higher than Kuwait (56.3\%) but lower than Sweden (88\%). It is notable that about $60 \%$ of the respondents in our study did not know that antibiotic 
resistance could spread from animal to human. Such misconception among the university students indicates that the percentage could be even higher among the general people, especially for the farmers who are often not well educated, as perceived through our field experience. According to a study conducted among African Americans, the lack of awareness about the use of medications such as antibiotics increased the likelihood of noncompliance and misuse of antibiotics [27]. Similar to a recently published study, our work demonstrated that the students of bioscience showed comparatively better knowledge and positive attitude while the faculty of arts had the highest percentage of poor knowledge and negative attitude followed by the faculty of business [28]. This is indicative of the importance of the inclusion of basic biology courses regarding bacteriology and antibiotics in the university level as well as developing educational programs and workshops to increase awareness among students about the misuse of medicines and the rise of antibiotic resistance [29].

The attitude of the participants was in the range of "neutral" viewpoint despite having an overall poor knowledge category. But notably, respondents, particularly with good knowledge, tended to show a positive attitude. This might explain that limited knowledge does not account for any strong correlation to positive attitude, whereas ensuring good knowledge can have a positive impact. This finding is supported by similar studies conducted in Ethiopia and Malaysia $[15,16]$. The majority of the participants in our study had a positive attitude about not acquiring antibiotics from a pharmacy without a prescription or based on the suggestion of the medicine seller. They were also against the opinion of obtaining a prescription from doctors via phone or acquiring medications from relatives. Telemedicine and Telehealth are not popular in Bangladesh, yet there is widespread malpractice of taking medicine via phone without going through proper diagnosis. The positive attitudes of the students about the misuse of antibiotics might contribute to mitigating the problem to some extent. Regarding leftover antibiotics, we reported about $27.4 \%$ students agreeing to save antibiotics for future-use or share with others, which is much lower than Saudi Arabia, Jordan, Nigeria and Pakistan but higher than Nepal, Italy, Sweden [4,19-22,24,26]. The storage of leftover antibiotics increases the likelihood of self-medication as well as consumption by others.

Self-medication is one of the major contributing factors for the development of antibiotic resistance. Although the majority considers antibiotic resistance is now a big problem for Bangladesh, self-medication yet occurs at an alarmingly high rate. Our study reported more than $60 \%$ of students practicing self-medication which is similar to Yemen but only lower than Saudi Arabia (70\%), Syria (81\%) and Palestine (87\%) $[22,23,30,31]$. In comparison, the percentage of selfmedication in New York, Trinidad \& Tobago, and Honduras ranges from $14 \%$ to $26 \%[13,32,33]$. However, the more improved scenario is observed in the European countries where the self-medication rate is within $5 \%$ only [34]. In the UK, people with better knowledge and a positive attitude about antibiotics were found to be more confident and hence more likely to self-medicate, but in our study, no such predictor could be attributed to self-medication among students [17]. It is an important finding based on our context that selfmedication occurs regardless of perceived knowledge or seemingly positive attitude. A study conducted on the students from the Jahangirnagar University, Dhaka, Bangladesh also returned similar results [28]. A comparable study conducted in Honduras showed that self-medication was not associated with the level of education [33]. Therefore, policy development targeted towards enriching knowledge only may not be fruitful; and it is open to further research to identify the underlying factors.

High frequency of antibiotic use was recorded in this study which is lower than Syria, Jordan and Italy, but comparatively much higher than Malaysia, the UK and other European countries $[16,17,20,23,26,34]$. The incidence of increased antibiotic use in Bangladesh could be partly due to the high disease burden in areas with inadequate water, sanitation, and hygiene facilities. But concurrently, patients' demand for antibiotics and a lack of knowledge in diagnosis by the physicians could contribute to the irrational consumption as well. Indeed, studies show that expectation of the patients is a key determinant and doctors are more likely to administer antibiotics under pressure [35]. According to our findings, about one-third of the participants had distrust about treatment and did not agree that doctors ran a thorough examination prior to prescribing. This underlines the importance of monitoring the antibiotic prescribing actions and consultancy behavior in the healthcare facilities along with deepening healthcare reform in Bangladesh. To prevent the irrational use of antibiotics, this study also emphasizes the need for pharmacies to adhere to the guidelines to stop selling antibiotics without a valid prescription. Nationwide inspection combined with educational campaigns should be undertaken for students, pharmacists as well as for the community members to improve awareness and to engage in communitybased dialogues to decrease the inappropriate use of antibiotics [36]

\section{Limitation}

Our study has a few limitations. First, the convenience sampling method was applied for data collection which renders the possibility for selection bias, and therefore the results cannot be generalized to the whole Bangladeshi people. Second, due to cross-sectional nature, it was not possible to determine behavior over a long period. Third, while creating knowledge and attitude score, each question was given same importance without undertaking any weighting. Fourth, the study was based on a self-administered questionnaire which largely depends on the understanding, recall ability and honestly of the study participants. Furthermore, we would like to mention that the study area, Dhaka city, provides comparatively better healthcare access and facilities than other areas. Therefore, it is plausible for results to vary for people in rural areas [37]. Also, we did not include any information in our study about students' socioeconomic background. This leaves out the options to see whether socioeconomic status have any role to play in determining attitude and behavior towards antibiotic use. Considering the limited literature available from Bangladesh, we believe that our study will add value to identify the scopes of the problems and help conduct future researches with more robust approaches. 


\section{CONCLUSION}

The study reflects that the overall understanding regarding antibiotics and their proper use was poor among the university students, although those with biology background showed comparatively better knowledge. Increased self-medication was observed with a general lack of comprehension towards antibiotic resistance; and the level of knowledge was not a predictor for self-medication. The frequency of antibiotic use was very high, and the students showed non-compliance to fulfilling the antibiotic course. This implies that further largescale research is necessary, both in urban and rural areas of Bangladesh, to understand the current states of antibiotic use and misuse among general population from different socioeconomic backgrounds. Development of policies aimed at raising awareness and establishing effective countermeasures to prevent the misuse of antibiotics are also essential.

Author contributions: All authors have sufficiently contributed to the study, and agreed with the results and conclusions.

Funding: No grants were involved in supporting this work.

Declaration of interest: The authors declare that there is no conflict of interest.

Acknowledgements: The authors would like to convey their immense gratitude to ASM Rubayet UI Alam for his guidance, and Md. Faysa Miah, Md. Sajib Miah, Shah Md Minhajul Abedin, Sakibur Rahat, Tanvir Ahmed Saikat, Arif Ishtiaq Sayim, Sunjida Afrin, Alfi Rashid, Abdul Hadi Nahid, Spencer Mark, and Mehedi Hasan Imran for their support during the data collection.

\section{REFERENCES}

1. Harbarth S, Samore MH. Antimicrobial Resistance Determinants and Future Control. Emerg Infect Dis. 2005 Jun;11(6):794-801. https://doi.org/10.3201/eid1106.050167 PMid:15963271 PMCid:PMC3367590

2. Islam S, Aldstadt J, Aga D. Global antimicrobial resistance: a complex and dire threat with few definite answers. Tropical Medicine \& International Health. 2019;24(6):65862. https://doi.org/10.1111/tmi.13230 PMid:30884021

3. Ayukekbong JA, Ntemgwa M, Atabe AN. The threat of antimicrobial resistance in developing countries: causes and control strategies. Antimicrob Resist Infect Control. 2017 May 15;6(1):47. https://doi.org/10.1186/s13756-0170208-x PMid:28515903 PMCid:PMC5433038

4. Vallin M, Polyzoi M, Marrone G, Rosales-Klintz S, Tegmark Wisell K, Stålsby Lundborg C. Knowledge and Attitudes towards Antibiotic Use and Resistance - A Latent Class Analysis of a Swedish Population-Based Sample. PLoS ONE. 2016;11(4):e0152160. https://doi.org/10.1371/ journal.pone.0152160 PMid:27096751 PMCid:PMC4838333

5. Pechère J-C, Hughes $D$, Kardas $P$, Cornaglia $G$. Noncompliance with antibiotic therapy for acute community infections: a global survey. Int J Antimicrob Agents. 2007 Mar;29(3):245-53. https://doi.org/10.1016/j.ijantimicag. 2006.09.026 PMid:17229552

6. Islam MA, Amin MB, Roy S, Asaduzzaman M, Islam MR, Navab-Daneshmand $T$, et al. Fecal Colonization With Multidrug-Resistant E. coli Among Healthy Infants in Rural Bangladesh. Front Microbiol. 2019 Apr 2;10:660. https://doi.org/10.3389/fmicb.2019.00640 PMid:31001224 PMCid:PMC6454046
7. Islam MA, Parveen S, Rahman M, Huq M, Nabi A, Khan ZUM, et al. Occurrence and Characterization of Methicillin Resistant Staphylococcus aureus in Processed Raw Foods and Ready-to-Eat Foods in an Urban Setting of a Developing Country. Front Microbiol. 2019 Mar 14;10:503. https://doi.org/10.3389/fmicb.2019.00503 PMid:30923520 PMCid:PMC6426745

8. Chowdhury F, Sturm-Ramirez $K$, Mamun AA, luliano AD, Chisti MJ, Ahmed M, et al. Effectiveness of an educational intervention to improve antibiotic dispensing practices for acute respiratory illness among drug sellers in pharmacies, a pilot study in Bangladesh. BMC Health Services Research. 2018 Aug 31;18(1):676. https://doi.org/10.1186/s12913018-3486-y PMid:30170573 PMCid:PMC6119333

9. WHO Global Strategy for Containment of Antimicrobial Resistance. World Health Organization; 2001. Available at: http://www.who.int/csr/resources/publications/drugresis t/en/EGlobal_Strat.pdf (Accessed: 16 April 2020).

10. Chen C, Chen Y-M, Hwang K-L, Lin S-J, Yang C-C, Tsay R-W, et al. Behavior, attitudes and knowledge about antibiotic usage among residents of Changhua, Taiwan. J Microbiol Immunol Infect. 2005 Feb;38(1):53-9.

11. Iskandar K, Molinier L, Hallit S, Sartelli M, Hardcastle TC, Haque $M$, et al. Surveillance of antimicrobial resistance in low- and middle-income countries: a scattered picture. Antimicrob Resist Infect Control. 2021 Dec;10(1):63. https://doi.org/10.1186/s13756-021-00931-w PMid:33789754 PMCid:PMC8011122

12. Jamshed SQ, Elkalmi R, Rajiah K, Al-Shami AK, Shamsudin $\mathrm{SH}$, Siddiqui MJA, et al. Understanding of antibiotic use and resistance among final-year pharmacy and medical students: a pilot study. J Infect Dev Ctries. 2014 Jun 11;8(6):780-5. https://doi.org/10.3855/jidc.3833 PMid: 24916878

13. Ahmad A, Khan MU, Patel I, Maharaj S, Pandey S, Dhingra S. Knowledge, attitude and practice of B.Sc. Pharmacy students about antibiotics in Trinidad and Tobago. J Res Pharm Pract. 2015 Mar;4(1):37-41. https://doi.org/10.4103/ 2279-042X.150057 PMid:25710049 PMCid:PMC4326970

14. Pavyde E, Veikutis V, Mačiulienè A, Mačiulis V, Petrikonis K, Stankevičius E. Public Knowledge, Beliefs and Behavior on Antibiotic Use and Self-Medication in Lithuania. Int J Environ Res Public Health. 2015 Jun 17;12(6):7002-16. https://doi.org/10.3390/ijerph120607002 PMid:26090612 PMCid:PMC4483745

15. Seid MA, Hussen MS. Knowledge and attitude towards antimicrobial resistance among final year undergraduate paramedical students at University of Gondar, Ethiopia. BMC Infect Dis. 2018 Dec;18(1):312. https://doi.org/10.1186 /s12879-018-3199-1 PMid:29980174 PMCid:PMC6035414

16. Lim KK, Teh CC. A Cross Sectional Study of Public Knowledge and Attitude towards Antibiotics in Putrajaya, Malaysia. South Med Rev. 2012 Dec 27;5(2):26-33.

17. McNulty CAM, Boyle P, Nichols T, Clappison P, Davey P. Don't wear me out-the public's knowledge of and attitudes to antibiotic use. J Antimicrob Chemother. 2007 Apr 1;59(4):727-38. https://doi.org/10.1093/jac/dkl558 PMid: 17307770

18. Awad Al, Aboud EA. Knowledge, Attitude and Practice towards Antibiotic Use among the Public in Kuwait. PLoS One. 2015 Feb 12;10(2):e0117910. https://doi.org/10.1371/ journal.pone.0117910 PMid:25675405 PMCid:PMC4326422 
19. Shah P, Shrestha R, Mao Z, Chen Y, Chen Y, Koju P, et al. Knowledge, Attitude, and Practice Associated with Antibiotic Use among University Students: A Survey in Nepal. Int J Environ Res Public Health. 2019 Oct;16(20):3996. https://doi.org/10.3390/ijerph16203996 PMid:31635429 PMCid:PMC6843929

20. Shehadeh M, Suaifan G, Darwish RM, Wazaify M, Zaru L, Alja'fari S. Knowledge, attitudes and behavior regarding antibiotics use and misuse among adults in the community of Jordan. A pilot study. Saudi Pharmaceutical Journal. 2012 Apr;20(2):125-33. https://doi.org/10.1016/j.jsps.2011. 11.005 PMid:23960783 PMCid:PMC3744980

21. Arshad MS, Rasool MF, ljaz M, Hussain A. Evaluation of Antibiotic Use Behaviour in Cold and Flu amongst the Students of Bahauddin Zakariya University Multan, Pakistan. Pak J Pharm. 2010; 23(2):15-22.

22. Al-Shibani N, Hamed A, Labban N, Al-Kattan R, Al-Otaibi H, Alfadda S. Knowledge, attitude and practice of antibiotic use and misuse among adults in Riyadh, Saudi Arabia. Saudi Med J. 2017 Oct;38(10):1038-44. https://doi.org/ 10.15537/smj.2017.10.19887 PMid:28917069 PMCid: PMC5694638

23. Barah F, Goncalves V. Antibiotic use and knowledge in the community in Kalamoon, Syrian Arab Republic: a crosssectional study. East Mediterr Health J. 2010 May 1;16(05):516-21. https://doi.org/10.26719/2010.16.5.516 PMid:20799551

24. Igbeneghu OA. Knowledge and practices in the use of antibiotics among a group of Nigerian university students. International Journal of Infection Control. 2013;09(01). https://doi.org/10.3396/ijic.v9i1.007.13

25. Ghadeer A. R. Y. Suaifan. A cross-sectional study on knowledge, attitude and behavior related to antibiotic use and resistance among medical and non-medical university students in Jordan. Afr J Pharm Pharmacol. 2012 Mar 15;6(10):763-770. https://doi.org/10.5897/AJPP12.080

26. Scaioli G, Gualano MR, Gili R, Masucci S, Bert F, Siliquini R. Antibiotic use: knowledge, attitudes and practices among health profession students in ItalyGiacomo Scaioli. Eur J Public Health. 2014 Oct 1;24(suppl_2):cku161-131. https://doi.org/10.1093/eurpub/cku161.131 PMid:25086246

27. Tina LK, James HP, Susan KT. Knowledge, beliefs, and use of prescribed antibiotic medications among lowsocioeconomic African Americans. Journal of the National Medical Association. 1996;88(5):289-294.

28. Marzan M, Islam DZ, Lugova $H$, Krishnapillai $A$, Haque $M$, Islam S. Knowledge, Attitudes, and Practices of Antimicrobial Uses and Resistance Among Public University Students in Bangladesh. IDR. 2021 Feb 11;14:519-33. https://doi.org/10.2147/IDR.S289964 PMid: 33603416 PMCid:PMC7886243
29. Bijani M, Hamidizadeh S, Rostami K, Haghshenas A, Mohammadi F, Ghasemi A, et al. Evaluation of the Effect of Clinical Scenario-Based Educational Workshop and Reflection on the Knowledge and Attitude of Head Nurses and Clinical Supervisors toward in the Brain Death and Organ Donation. Electron J Gen Med. 2020 Apr 5;17(5):em233. https://doi.org/10.29333/ejgm/7903

30. Mohanna M. Self-medication with Antibiotic in Children in Sana'a City, Yemen. Oman Med J. 2010 Jan;25(1):41-3. https://doi.org/10.5001/omj.2010.10 PMid:22125697 PMCid:PMC3215380

31. Al-Ramahi R. Patterns and attitudes of self-medication practices and possible role of community pharmacists in Palestine. Int J Clin Pharmacol Ther. 2013 Jul;51(7):562-7. https://doi.org/10.5414/CP201814 PMid:23587151

32. Ceaser S, Wurtz R. "Leftover" Antibiotics in the Medicine Cabinet. 2000. https://doi.org/10.7326/0003-4819-133-1200007040-00017 PMid:10877746

33. Crigger NJ, Holcomb L, Grogan RL, Vasquez M, Parchment C, Almendares J, et al. Development of the choices and acquisition of antibiotics model from a descriptive study of a lay Honduran population. Int J Nurs Stud. 2004 Sep;41(7):745-53. https://doi.org/10.1016/j.ijnurstu.2004. 03.001 PMid: 15288797

34. European Commission (2013) Special Eurobarometer 407 Antimicrobial resistance. TNS Opinion \& Social. Available at: http://ec.europa.eu/health/antimicrobial_resistance/ docs/ebs_407_en.pdf (Accessed: 16 April 2020).

35. Ong S, Nakase J, Moran GJ, Karras DJ, Kuehnert MJ, Talan DA, et al. Antibiotic use for emergency department patients with upper respiratory infections: prescribing practices, patient expectations, and patient satisfaction. Ann Emerg Med. 2007 Sep;50(3):213-20. https://doi.org/10.1016/ j.annemergmed.2007.03.026 PMid:17467120

36. King R, Hicks J, Rassi C, Shafique M, Barua D, Bhowmik P, et al. A process for developing a sustainable and scalable approach to community engagement: community dialogue approach for addressing the drivers of antibiotic resistance in Bangladesh. BMC Public Health. 2020 Dec;20(1):950. https://doi.org/10.1186/s12889-020-09033-5 PMid:32552687 PMCid:PMC7302129

37. Ahmed S, Ali MM, Hasan J. Knowledge, Attitudes, Practices and Perceptions on COVID-19 among University Students in Bangladesh. Journal of Contemporary Studies in Epidemiology and Public Health. 2021 Jan 4;2(1):ep21003. https://doi.org/10.30935/jconseph/9366 